Viti i XII ${ }^{-t e ̈ ~} \mathrm{i}$ Botimit, Nr.1-2,

Dhjetor 2020

\title{
BURIMET DHE BENEFITET E VITAMINËS C
}

\author{
Krenaida Taraj*, Asela Hasa**, Alba Muca**
}

*Albanian University, Fakulteti i Shkencave Mjekësore Departamenti i Farmacisë

**Universiteti i Tiranës, Fakulteti i Shkencave të Natyrës, Departamenti i Kimisë

Adresë kontakti: k.taraj@albanianuniversity.edu.al;

\section{Përmbledhje}

Vitamina $C$ ka një rëndësi shumë të madhe në dietën ushqimore të çdo individi, prandaj është i rëndësishëm ndërgjegjësimi i secilit prej nesh lidhur me burimet e Vitaminës C në produktet ushqimore të cilat ne konsumojmë, doza e rekomanduar ditore dhe rastet e marrjes së Vitaminës C nëpërmjet suplementeve. Bazuar në të dhënat e përpunuara të pyetësorit mund të themi se 69\% e kampionimit shprehen se synojnë që Vitaminën $C$ ta marrë nëpërmjet regjimit ushqimor. Gjithashtu, $43 \%$ e kampionimit shprehen se rrisin përdorimin e produkteve ushqimore të cilat përmbajnë Vitaminën $C$ gjatë stinës së dimrit në mënyrë që të mbrohen nga virozat stinore. 74\% e kampionimit është shprehur se prania e Vitaminës C në produkte të caktuara ushqimore ndikon në vendimin e tyre për të konsumuar disa produkte ushqimore. $51 \%$ e kampionimit është shprehur se do të rriste konsumin e produkteve të cilat përmbajnë Vitaminën C si pasojë e informacionit që do të kishte për produktin. 64\% e kampionimit janë shprehur se kanë rritur konsumin e produkteve ushqimore të cilat përmbajnë Vitaminën $C$ gjatë situatës së Covid-19, dhe $43 \%$ e kampionimit shprehen se disa herë synojnë të përfshijnë në dietën ushqimore të fëmijëve të tyre produkte të cilat përmbajnë Vitaminën $C$.

Fjalë çelës: Vitamina $C$; burimet; benefitet; ushqim; suplement

\section{SOURCES AND BENEFITS OF VITAMIN C}

\section{Abstract}

Vitamin C is very important in the diet of each individual, so it is important to make each of us aware of the sources of Vitamin $\mathrm{C}$ in the food products we consume, the recommended daily dose and cases of taking Vitamin $\mathrm{C}$ through supplements. Based on the processed data of the questionnaire we can say that $69 \%$ of the sample stated that they intend to get Vitamin $\mathrm{C}$ through the diet. Also, $43 \%$ of the sample say that they increase the use of food products which contain Vitamin C during the winter season in order to protect themselves from seasonal viruses. $74 \%$ of the sample stated that the presence of Vitamin $\mathrm{C}$ in 
BURIMET DHE BENEFITET E VITAMINËS C

certain food products influences their decision to consume certain food products. $51 \%$ of the sample stated that they would increase the consumption of products that contain Vitamin $\mathrm{C}$ as a result of the information they would have about the product. $64 \%$ of the sample stated that they have increased the consumption of food products that contain Vitamin $\mathrm{C}$ during the Covid-19 situation, and $43 \%$ of the sample stated that sometimes they intend to include in their children's diet products that contain Vitamin C.

Key words: Vitamin C; sources; benefit; food; supplement.

\section{Hyrje}

Studimet kanë treguar që vitamina C mund të parandalojë ose trajtojë ftohjen në situata mesatare. Përfitimet e antioksidantit të vitaminës $C$ janë gjithashtu të paqarta. Ndërsa disa studime mbi suplementet e vitaminës $C$ kanë qenë premtuese, ata nuk kanë gjetur prova të forta që suplementet e vitaminës C ndihmojnë në sëmundjen e kancerit, goditjes në tru, astmën dhe shumë sëmundje të tjera. Disa prova sugjerojnë se vitamina C mund të jetë e dobishme në njerëzit që kanë kolesterol të lartë dhe në parandalimin e kataraktit, por nevojiten më shumë studime për të provuar këto efekte. Disa studime tregojnë një lidhje midis niveleve të ulëta të vitaminës $C$ dhe rrezikut të sëmundjeve të zemrës, megjithatë shumë studime kanë lidhur përdorimin e suplementeve të vitaminës $C$ me një rrezik të shtuar të sëmundjeve të zemrës. Të dhënat për ndikimin e vitaminës $C$ për hipertensionin janë gjithashtu të përziera ${ }^{1-3}$. Studimet kanë treguar se regjimi ushqimor më shumë sesa burimet plotësuese të vitaminës $\mathrm{C}$ janë më efektive në mbajtjen e kontrollit të presionit të gjakut. Vitamina $\mathrm{C}$ gjithashtu duket se ndihmon trupin të thithë hekurin mineral. Aktualisht, edhe për shkak të pandemisë botërore Covid-19, vëmendja është kthyer dhe intensifikuar lidhur me rolin e Vih taminës $C^{4-7}$. Ekzistojnë pak studime të cilat tregojnë se doza të larta të vitaminës $C$ e marrë në rrugë orale ose (intravenoze) parandalojnë COVID-19. Më shumë hulumtime janë duke u zhvilluar për të kuptuar më mirë sesi mund të përdorim vitaminën IV për të ndihmuar në trajtimin e COVID-19. Studimet tregojnë se konsumimi i më shumë vitaminës C mund të rrisë nivelin e antioksidantës në gjak deri në 30\%. Kjo ndihmon mbrojtjen natyrore të trupit për të luftuar inflamacionin ${ }^{8}$. Vitamina $\mathrm{C}$ gjendet në shumë fruta dhe perime, përfshirë portokallin, luleshtrydhen, frutat e kivit, specat, brokolit, lakër kale, dhe spinaqi. Sasia e rekomanduar ditore për vitaminë C është $75 \mathrm{mg}$ për gratë dhe $90 \mathrm{mg}$ për burra. Duke qënë se zakonisht këshillohet marrja e vitaminës C nga ushqimet, shumë njerëz iu drejtohen suplementeve 
Krenaida Taraj, Asela Hasa, Alba Muca

për të përmbushur nevojat e tyre ${ }^{9}$. Vlera ditore (DV) për vitaminën C është $90 \mathrm{mg}$ në ditë, por gratë që ushqehen me gji kanë nevojë për $30 \mathrm{mg}$ shtesë dhe njerëzit që pinë duhan kanë nevojë për një shtesë prej $35 \mathrm{mg}$ në ditë. Është shumë e thjeshtë për të përmbushur nevojat e individit për vitaminën $\mathrm{C}$ përmes dietës ushqimore për sa kohë hani një larmi frutash dhe perimesh. Për shembull, një portokall i vetëm i mesëm siguron $77 \%$ të DV, dhe 1 filxhan (160 gram) brokoli i gatuar siguron $112 \%$ të DV ${ }^{10}$.

\section{Metodologjia}

\section{Kampionimi i studimit}

Kampionimi i studimit, do të synojë të pasqyrojë një qasje lidhur me burimet e Vitaminës $\mathrm{C}$ dhe benefitet e saj sipas perceptimit të kampionimit. Masat e ndërmarra nga qeveria për parandalimin e Covid-19 kanë reduktuar mundësitë për të lëvizur dhe për të aksesuar fizikisht disa burime informacioni, por në përputhje me objektin e studimit do të fokusohemi te informacioni online. Në këtë aspekt, kampionimi do të përbëhet nga 200 (dyqind) qytetarë. Gjithashtu, në studim jepen produktet ushqimore, doza e tyre dhe prania e Vitaminës C, si dhe doza e rekomanduar ditore për kategori të ndryshme të popullësisë.

\section{Analiza e të dhënave}

Janë realizuar rreth 10 pyetje në pyetësor te cilat paraqiten grafikisht më poshtë së bashku dhe me përgjigjet për secilën. Lidhur me pyetjen e parë të studimit e cila synon të jap një përgjigje mbi gjininë e kampionimit rezulton se 73\% e kampionimit të cilët i janë përgjigjur pyetjeve të pyetësorit i përkasin gjinisë femërore, dhe vetëm $27 \%$ e kampionimit i përkasin gjinisë mashkullore. Të dhënat paraqiten në mënyrë grafike, si në grafikun nr.1.

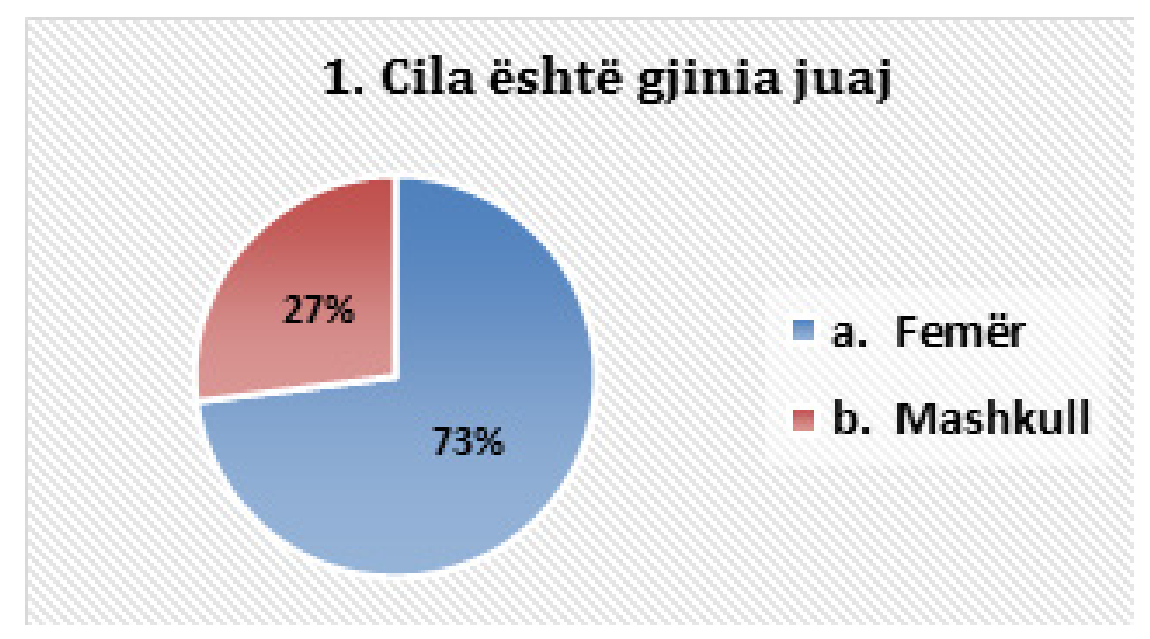

Grafiku 1. Gjinia e kampionimit 


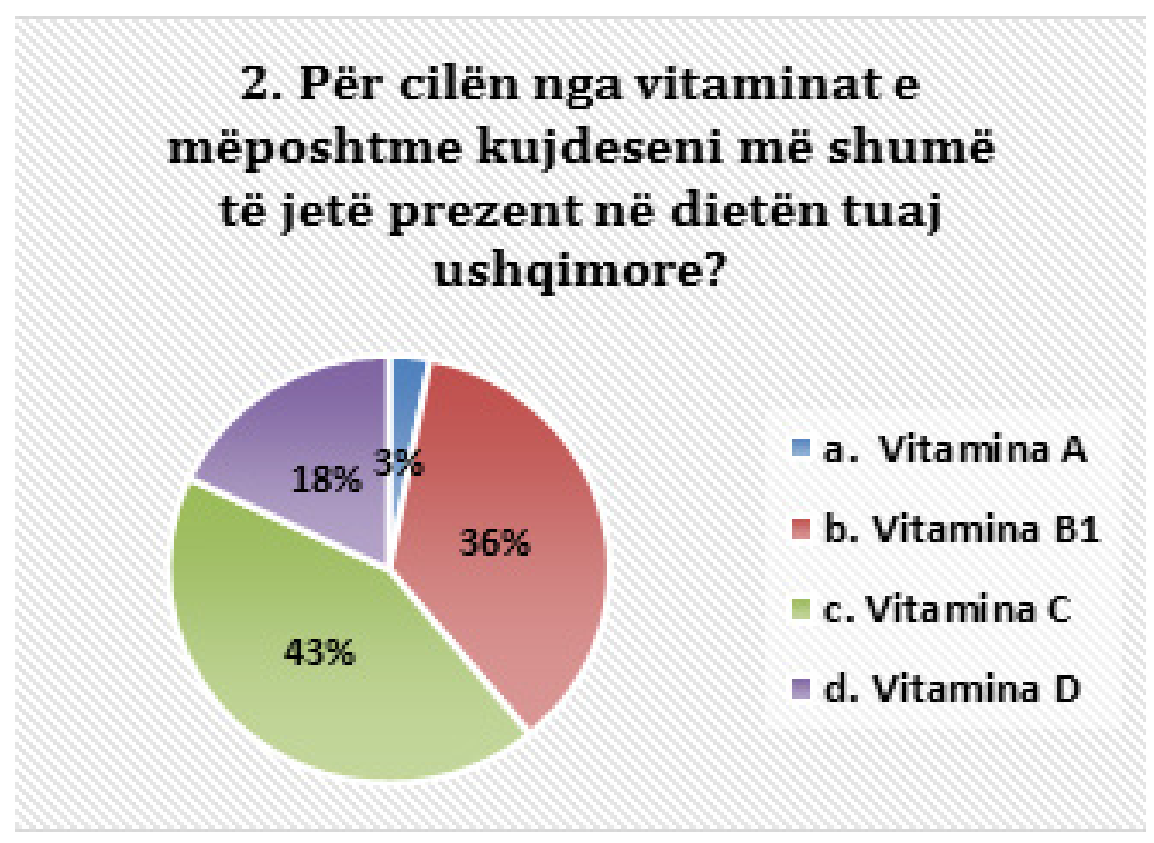

Grafiku 2. Për cilën nga vitaminat e mëposhtme kujdeseni më shumë që të jetë prezent në dietën tuaj ushqimore

\section{A konsumoni produkte bazuar në njohuritë se ato kanë Vitaminë}

c?

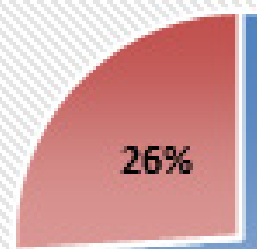

a. Po

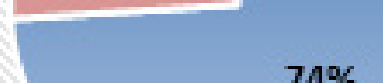

n b. Jo

Grafiku 3. A konsumoni produkte bazuar në informacionet që keni se ato përmbajnë Vitaminën C 


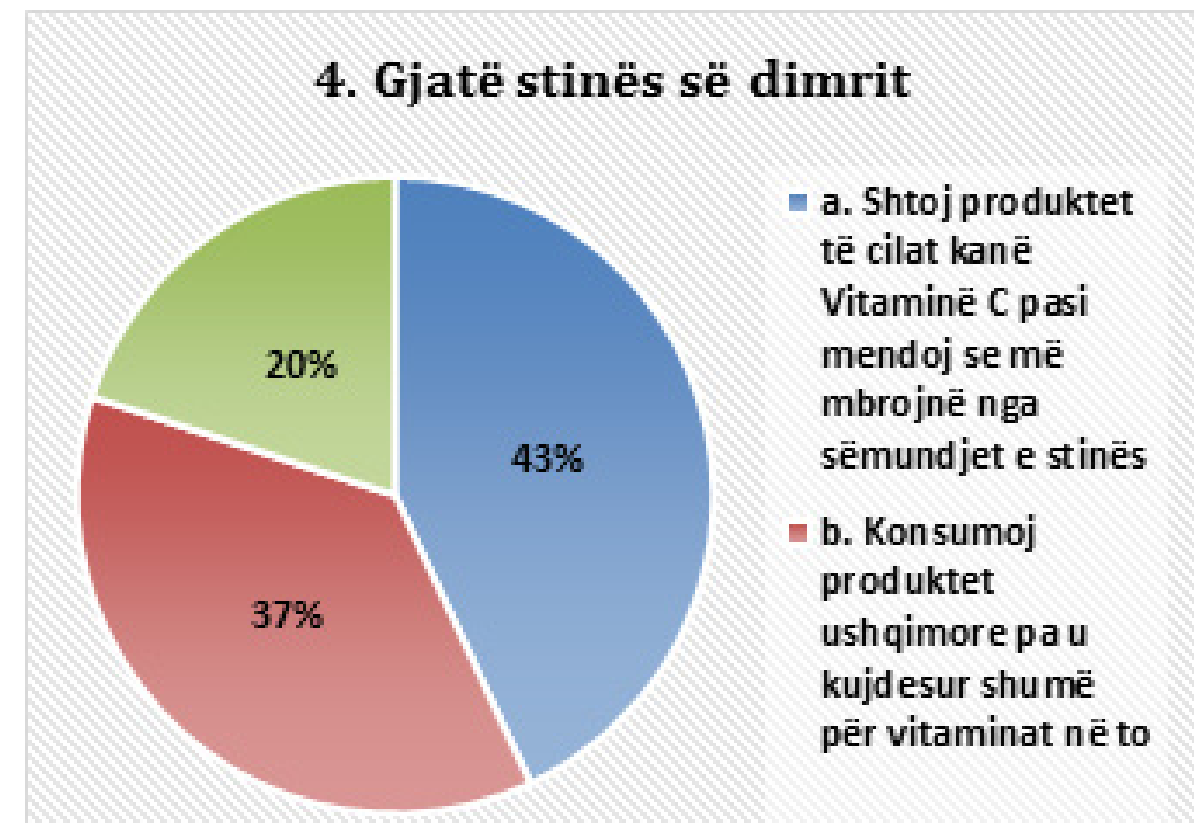

Grafiku 4. Konsumi i produkteve të cilat përmbajnë Vitaminë C gjatë stinës së dimrit (mbrojtje ndaj viroza stinore)

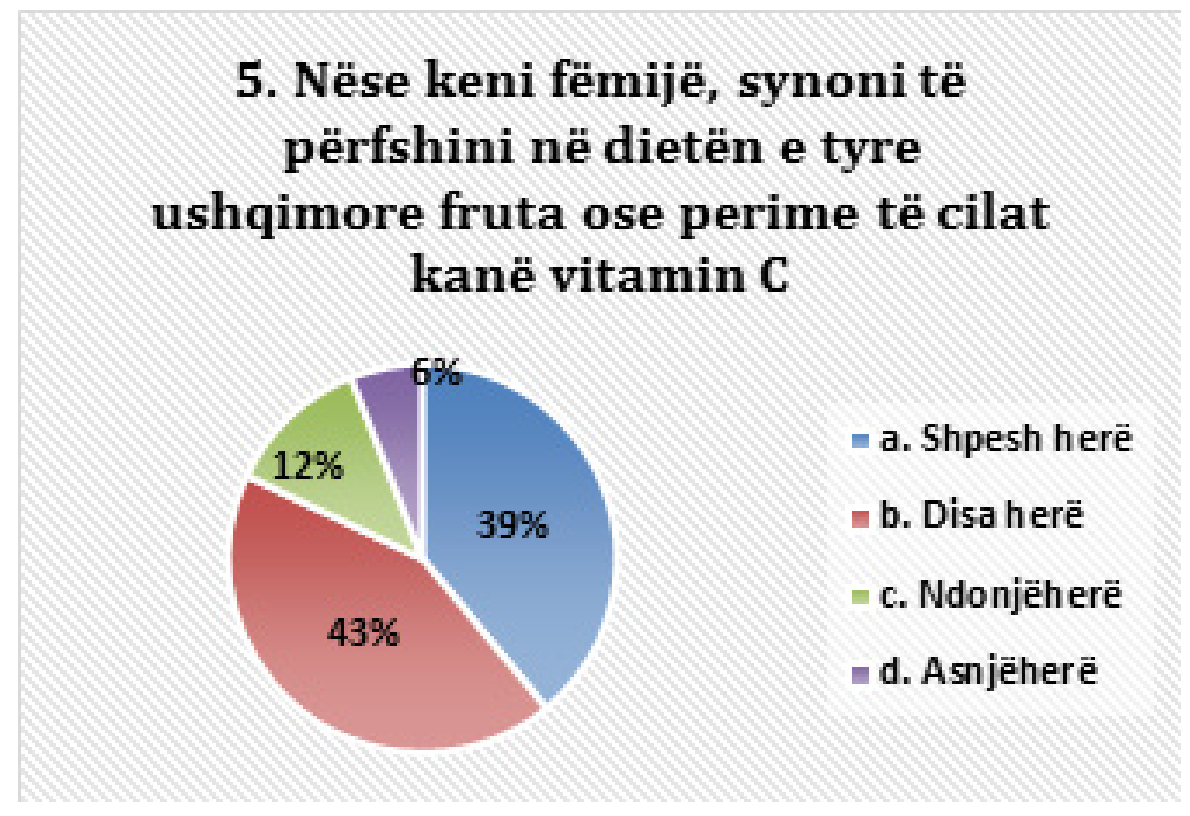

Grafiku 5. Sjellja e kampionimit për përfshirjen e produkteve të cilët përmbajnë Vitaminë $C$ në dietën ushqimore të fëmijëve 


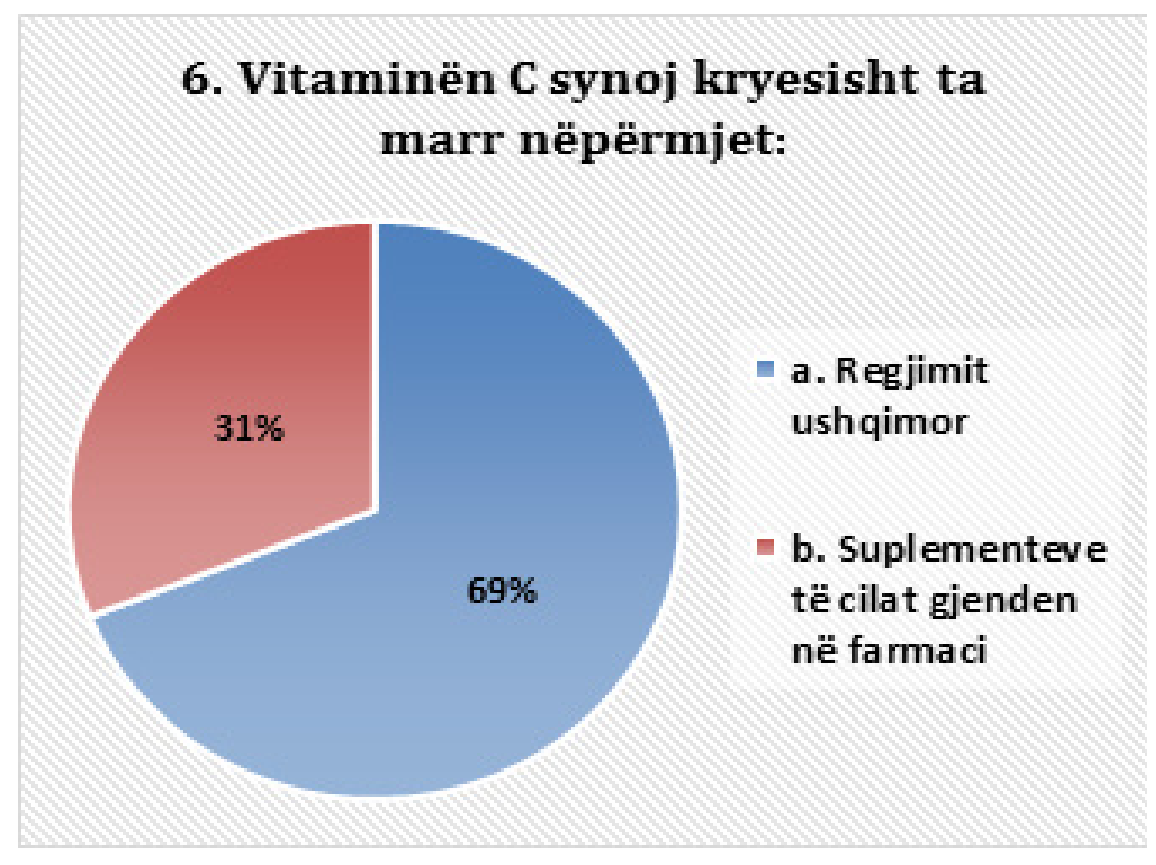

Grafiku 6. Burimi i vitaminës C

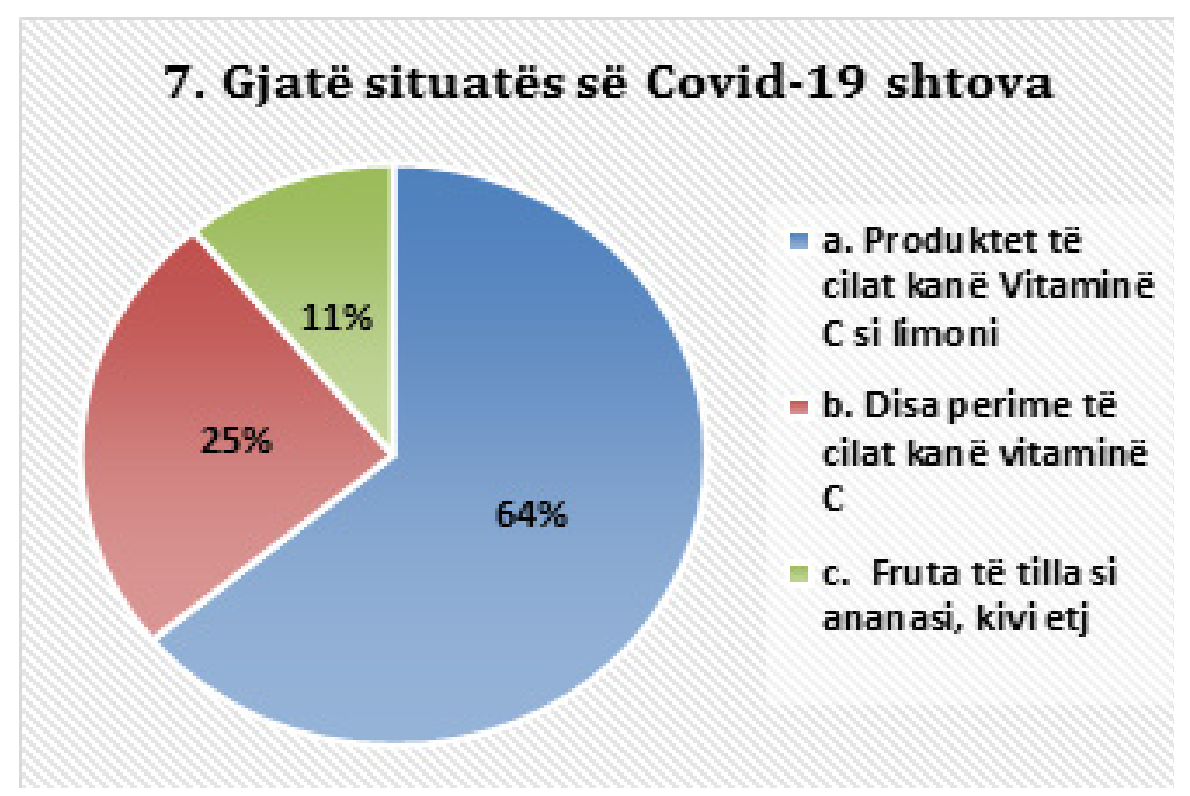

Grafiku 7. Si ka ndikuar situata e Covid-19 në shtimin e produkteve të cilat përmbajnë Vitaminë C 


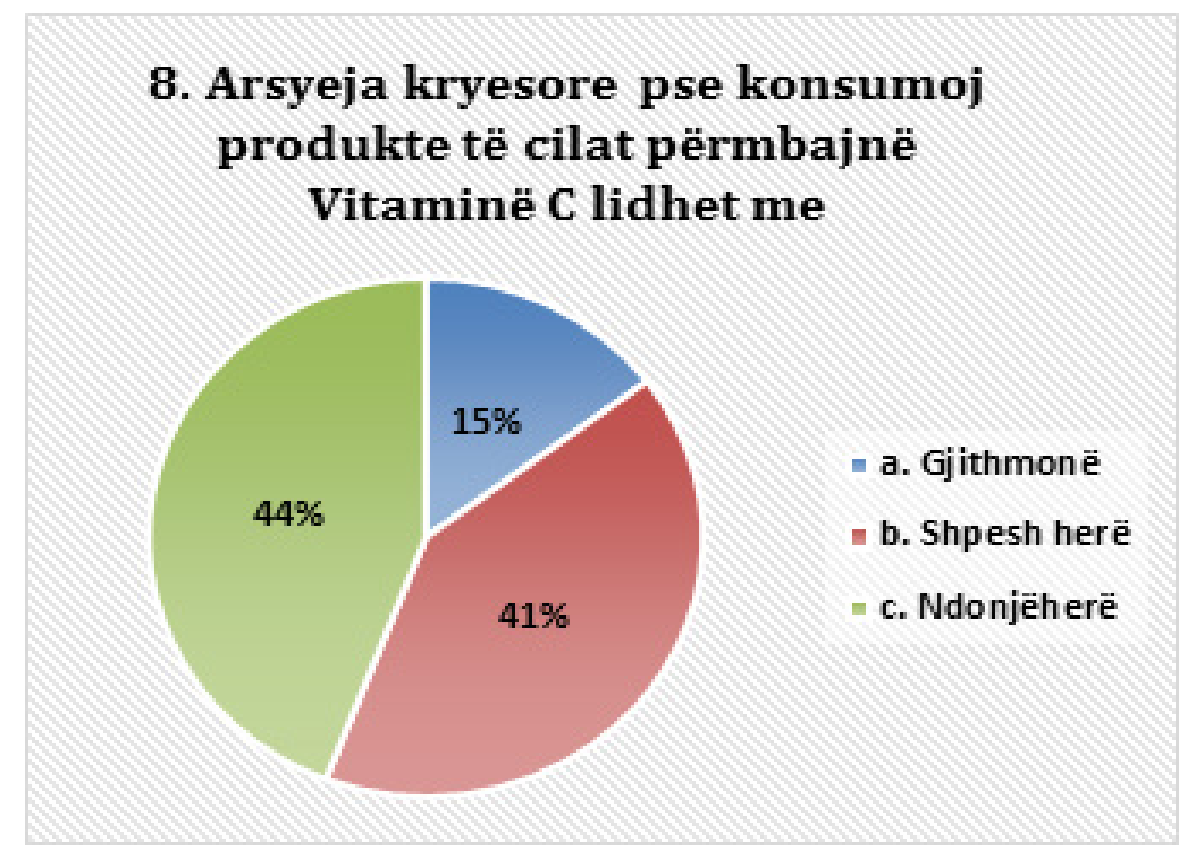

Grafiku 8. Cila është arsyeja kryesore pse njerëzit konsumojnë proukte të cilat përmbajnë Vitaminën $C$

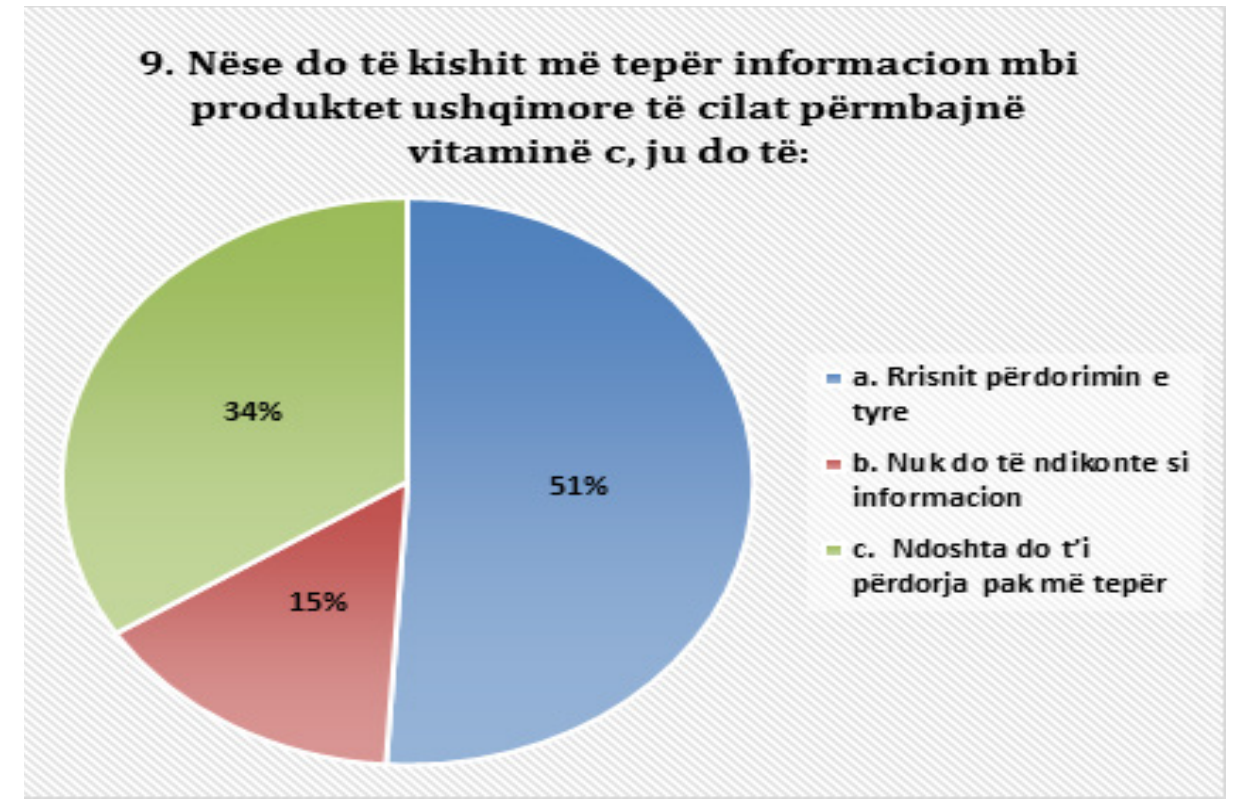

Grafiku 9. Nevoja për të pasur më tepër informacion mbi burimet e Vitaminës C 


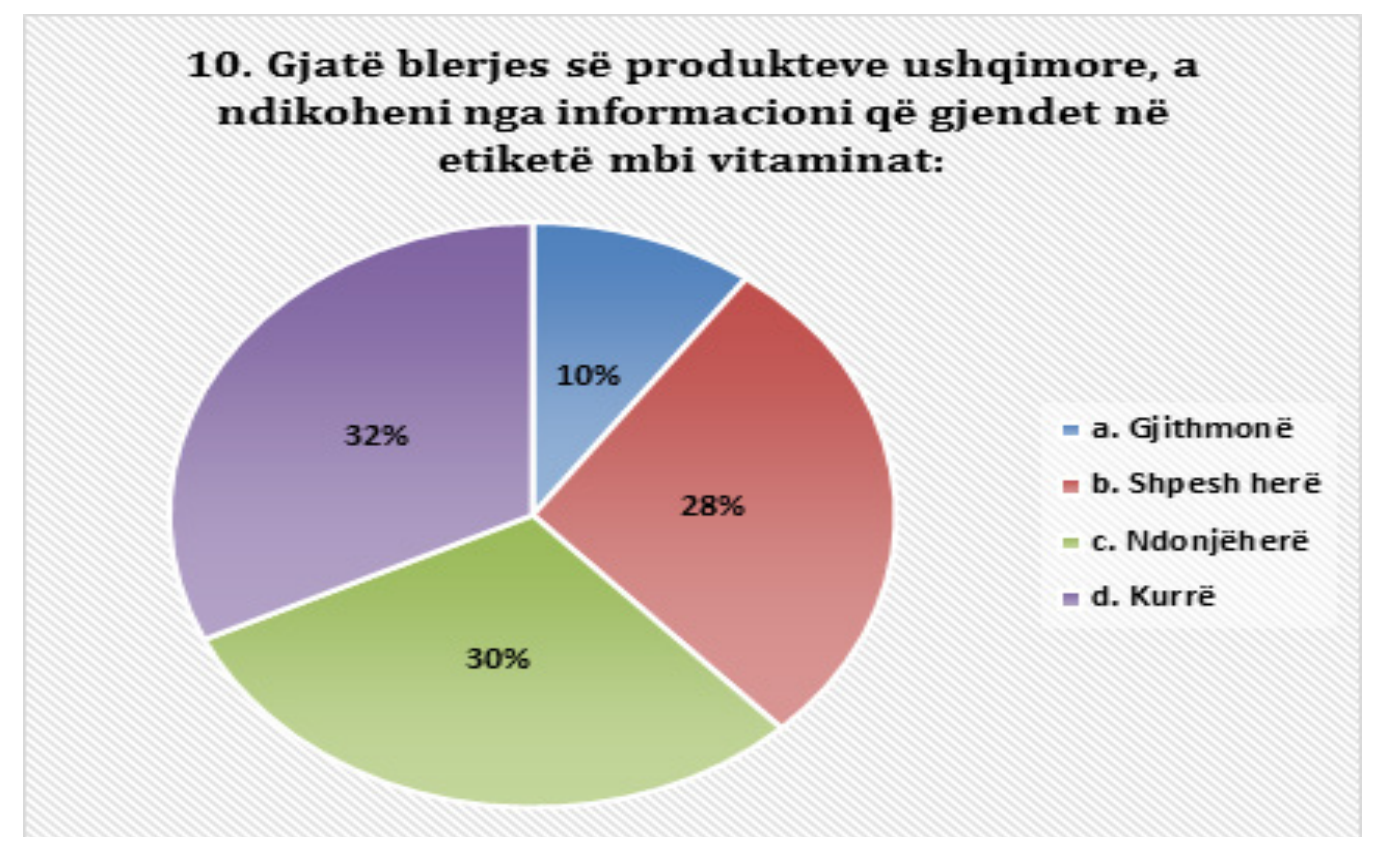

\section{Grafiku 10. Sa ndikon gjatë blerjes së produkteve ushqimore informacioni që gjendet në etiketë mbi vitaminat}

\section{Konkluzione}

Vitamina C ndikon në shëndetin e pacientit dhe forcimin e sistemit imunitar në disa mënyra. Aktiviteti i tij antioksidues mund të ulë inflamacionin, i cili mund të ndihmojë në përmirësimin e funksionit imunitar. Vitamina $C$ gjithashtu mban të shëndetshme lëkurën duke rritur prodhimin e kolagjenit, duke ndihmuar lëkurën të shërbejë si një pengesë funksionale për të mbajtur komponimet e dëmshme nga hyrja në trupin e pacientit. Vitamina $\mathrm{C}$ gjithashtu rrit aktivitetin e fagociteve, qelizave imune. Përveç kësaj, Vitamina $\mathrm{C}$ promovon rritjen dhe përhapjen e limfociteve, një lloj qelizash imune që rrit antitrupat qarkullues, dhe proteinat që mund të sulmojnë substanca të huaja ose të dëmshme në gjakun e individit. Në studimet mbi efektivitetin e vitaminës C kundër viruseve që shkaktojnë ftohjen e zakonshme, vitamina $C$ nuk duket se parandalon mundësinë për të pasur një ftohje, por mund të ndihmojë individët të kalojnë më shpejt një ftohje dhe t'i bëjë simptomat më pak të rënda. Ekzistojnë gjithashtu hulumtime të cilat tregojnë se që me dozë të lartë ose vitamina $C$ mund të zvogëlojë inflamacionin e mushkërive në sëmundje të rënda të frymëmarrjes të shkaktuara ngaH1N1 ("gripi i derrit”) ose viruse të tjera. Gjithsesi pavarësisht benefiteve të vitaminës C, studimet kanë treguar që nuk rekomandohet përdorimi në doza të larta pasi mund të shkaktojnë gjithashtu efekte anësore. Lidhur me burimet e Vitaminës C, rezultatet e pyetësorit të plotësuar nga 
Krenaida Taraj, Asela Hasa, Alba Muca

kampionimi rezulton se $69 \%$ e kampionimit shprehen se synojnë që Vitaminën C ta marrë nëpërmjet regjimit ushqimor. Gjithashtu, 43\% e kampionimit shprehen se rrisin përdorimin e produkteve ushqimore të cilat përmbajnë Vitaminën $C$ gjatë stinës së dimrit në mënyrë që të mbrohen nga virozat stinore. 74\% e kampionimit është shprehur se prania e Vitaminës C në produkte të caktuara ushqimore ndikon në vendimin e tyre për të konsumuar disa produkte ushqimore. $51 \%$ e kampionimit është shprehur se do të rriste konsumin e produkteve të cilat përmbajnë Vitaminën C si pasojë e informacionit që do të kishte për produktin. 64\% e kampionimit janë shprehur se kanë rritur konsumin e produkteve ushqimore të cilat përmbajnë Vitaminën C gjatë situatës së Covid-19, dhe 43\% e kampionimit shprehen se disa herë synojnë të përfshijnë në dietën ushqimore të fëmijëve të tyre produkte të cilat përmbajnë Vitaminën $C$. Në mënyrë të përgjithshme rezulton se kampionimi ka informacion përgjithësisht mbi burimet dhe benefitet e Vitaminës $C$ dhe bazuar në benefitet e prezantuara të saj synon që të marrë vitaminën $C$ nëpërmjet regjimit ushqimor kryesisht.

\section{Rekomandime}

Në mënyrë që të rritet konsumi i produkteve të cilat përmbajnë vitaminën $C$ rekomandohet:

- Të rritet informacioni mbi produktet në të cilat gjendet Vitamina C, duke nisur që nga mosha shkollore dhe duke përmendur gjithashtu edhe pasqyrimin e këtij informacioni në etiketat e produkteve ushqimore,

- Të konsolidohen qëndrimet shkencore lidhur me benefitet e provuara shkencërisht si pasojë e konsumimit të produkteve të cilat përmbajnë Vitaminën C.

\section{Referenca}

1. Moser, M. A., \& Chun, O. K; Vitamin C and heart health: a review based on findings from epidemiologic studies. 2016 International journal of molecular sciences, 17(8), 1328.

2. Naidu, K. A.; Vitamin C in human health and disease is still a mystery? An overview. 2003 Nutrition journal, 2(1), 7.

3. Valdés, F. Vitamina C. Actas dermo-sifiliográficas, 2006 97(9), 557-568.

4. Sauberlich, H. E.; Pharmacology of vitamin C. Annual review of nutrition, 1994. 14(1), 371-391.

5. Lemon, S. C., Rosal, M. C., Zapka, J., Borg, A., \& Andersen, V.; Contributions of weight perceptions to weight loss attempts: differences by body mass index and gender. Body image, 2009, 6(2), 90-96. 


\section{BURIMET DHE BENEFITET E VITAMINËS C}

6. Levine, M., Conry-Cantilena, C., Wang, Y., Welch, R. W., Washko, P. W., Dhariwal, K. R., ... \& Cantilena, L. R.; Vitamin C pharmacokinetics in healthy volunteers: evidence for a recommended dietary allowance. 1996 Proceedings of the National Academy of Sciences, 93(8), 3704-3709.

7. Levine, M., Wang, Y., Padayatty, S. J., \& Morrow, J.; A new recommended dietary allowance of vitamin $\mathrm{C}$ for healthy young women. 2001 Proceedings of the National Academy of Sciences, 98(17), 9842-9846.

8. Rocha, S. D., Capanema, F. D., Netto, M. P., Franceschini, C. S., \& Lamounier, J. A.; Effectiveness of fortification of drinking water with iron and vitamin $\mathrm{C}$ in the reduction of anemia and improvement of nutritional status in children attending day-care centers in Belo Horizonte, Brazil. 2011 Food and nutrition bulletin, 32(4), 340-346.

9. Lopez-Varela, S., Gonzalez-Gross, M., \& Marcos, A.; Functional foods and the immune system: a review. 2002 European Journal of Clinical Nutrition, 56(3), S29-S33.

10. Mohanapriya, M., Ramaswamy, L., \& Rajendran, R. Health and medicinal properties of lemon (Citrus limonum). 2013 International Journal of Ayurvedic and Herbal Medicine, 3(1), 1095-1100 